\title{
Pattern and Extent of Street Food Consumption in Hohoe, Volta Region, Ghana: A Community-Based Cross-Sectional Survey
}

\author{
Winnifred Ekua Baidoe, ${ }^{1}$ Mark Kwame Ananga $\mathbb{D D}^{2}{ }^{2}$ and Elorm Kwame Nyinaku ${ }^{3}$ \\ ${ }^{1}$ Department of Family and Community Health, School of Public Health, University of Health and Allied Sciences, Hohoe, Ghana \\ ${ }^{2}$ Department of Population \& Behavioural Sciences, School of Public Health, University of Health and Allied Sciences, \\ Hohoe, Ghana \\ ${ }^{3}$ Department of Health Information Management, College of Health, Yamfo, Ghana
}

Correspondence should be addressed to Mark Kwame Ananga; kananga@uhas.edu.gh

Received 22 November 2019; Revised 29 May 2020; Accepted 30 June 2020; Published 18 July 2020

Academic Editor: Susana Fiszman

Copyright ( 2020 Winnifred Ekua Baidoe et al. This is an open access article distributed under the Creative Commons Attribution License, which permits unrestricted use, distribution, and reproduction in any medium, provided the original work is properly cited.

\begin{abstract}
Background. For most people in developing countries, street food is a major source of sustenance, and Ghana is no exception. Street food vending has seen tremendous growth in Ghana as a result of the insurgence of urbanisation. Despite being one of the largest sectors of national economy in terms of employment and sales of food, very little is known about street food consumption patterns in Ghana. The current study explored the patterns and extent of street food consumption in the Hohoe township. Methods. A cross-sectional design which recruited 403 subjects through a multistage sampling technique. A semistructured questionnaire was used to gather information on demographics, types of street foods, extent of street food consumption, safety concerns, and diversity of street foods patronised. Means, standard deviations, and Chi-square tests were used to determine the association between selected variables at $<0.05$ level of significance. Results. The top 5 foods mostly patronised by respondents are porridge foods-Koko (17.9\%), rice and stew (17.4\%), banku (12.6\%), waakye (11.5\%), and kenkey (8.7\%) with porridge foods consumed almost on a daily basis. Convenience (37.2\%) and affordability (17.1\%) greatly influenced the choice of street foods among consumers. Occupation and the level of education are strongly correlated with the concern for safety of street foods $\left\{\left(X^{2}=17.3094, P<0.008\right) ;\left(X^{2}=17.1731, P<0.002\right)\right\}$. The dietary diversity score of most respondents was in the high tercile (77.7\%) ( $\geq 6$ food groups), whilst the cereals dominate the food group mostly consumed by respondents. Conclusion. The study suggests that patronising street food is very high in Hohoe municipality, irrespective of the gender, occupation, or educational level. As an "informal" sector of food business, street foods often escape formal inspection and control. They can, therefore, both be the source of food safety problems and contribute to the deterioration of environmental hygiene. This is a call on policy makers and regulators to take a critical look at the sector.
\end{abstract}

\section{Introduction}

Street foods may be the least expensive and most accessible means of obtaining a nutritionally balanced meal outside the home for many low-income people, provided that the consumer is informed and able to choose the proper combination of foods [1]. It represents a major part of food consumptions for millions of people of low- and-middleincome consumers, in urban areas on a daily basis, and Ghana is no exception [2]. Traditional Ghanaian dishes based on local cuisine include fufu (pounded cassava mixed with either plantain or cocoyam), kenkey-Ga and fante kenkey (cooked fermented maize wrapped in corn husks or plantain leaves), banku (cooked fermented corn dough), fried yam, and game meat. Others include kelewele (fried pieces of cubed ripped plantains marinated in a spicy pepper sauce) and konkonte (meal made from flour of milled sundried cassava) [3].

There has been a phenomenal increase in the activities of street food vendors in the Hohoe Municipality over the last few decades. The influx of working people and students into the municipality, with the majority of such people traveling 
long distances between their work places/schools and their residences, compels them to rely on street-vended foods, which are more convenient and readier to eat. However, there is a paucity of data and research on the street food consumptions pattern in Ghana. Few studies on streetvended foods in Ghana were limited to concerns on the safety of street foods $[4,5]$. The literature indicates that consumer concerns about food safety, in general, differ according to demographic and socioeconomic factors such as the gender, age, educational level, and economic status [4-7]. Whilst the main reason for patronizing street foods has always been diverse depending on the research setting, convenience, accessibility, and cost have always been considered [8-10].

The objective of the current study is to explore the nature and pattern of street food consumption in the Hohoe township, specifically, the types and diversity of street food consumed, extend of such consumption, factors underlying consumption, and assessing consumers' perception of safety of street food. This could provide information that would be valuable in designing training programmes to sensitize consumers to demand high quality and safe foods from vendors.

\section{Method}

2.1. Study Design. This cross-sectional study was conducted among a sample of six socioeconomically diverse suburbs throughout Hohoe (Bla, Kpeme, Zongo, Ahado, Kpoeta, and Market Area). A semistructured questionnaire developed by the research team together with the Dietary Diversity Scale was used to collect data.

2.2. Study Site. The Hohoe Municipality is one of the 25 administrative districts/municipalities in the Volta region of Ghana. The municipality has a total land surface area of $1,172 \mathrm{~km}$ square, which is $5.6 \%$ of the regional and $0.05 \%$ of the national land surface area. According to the 2010 population census, Hohoe has a total population of 167,016 , representing 7.9 percent of the total population of the Volta Region. Some economic activities engaged by the people of the municipality include agriculture, petty trading, construction, and formal sector employment.

The ethnic composition of Hohoe is comprised mainly of the Ewe group. However, there are the Dagombas, other Guan ethnic groups such as the Likpe and the Lolobi, and few Ga-Adangme and Akan-speaking groups.

2.3. Study Population. The study targeted adult population residing in the Hohoe township. The sampling frame included persons aged between 18 and 60 years. Only a cross section of the population who met the inclusion criteria was interviewed. This owed to the fact that time and other resources did not permit conducting a study that will cover all people in the municipality meeting the eligibility criteria. Such individuals must have been residing in Hohoe for the past 6 months.
TABLE 1: Demographic characteristics of respondents.

\begin{tabular}{|c|c|c|}
\hline $\begin{array}{l}\text { Variables } \\
\text { Mean (SD) }\end{array}$ & $\begin{array}{c}\text { Frequency }(n=403) \\
28.79(8.38)\end{array}$ & Percentage (100\%) \\
\hline \multicolumn{3}{|l|}{ Age (group) } \\
\hline Below 25 years & 160 & 39.7 \\
\hline 25 to 29 years & 93 & 23.2 \\
\hline 30 to 34 years & 59 & 14.6 \\
\hline 35 to 39 years & 37 & 9.2 \\
\hline 40 to 45 years & 25 & 6.2 \\
\hline 45 to 49 years & 17 & 4.2 \\
\hline 50 and above & 12 & 3 \\
\hline \multicolumn{3}{|l|}{ Sex } \\
\hline Female & 172 & 42.7 \\
\hline Male & 231 & 57.3 \\
\hline \multicolumn{3}{|l|}{ Marital status } \\
\hline Married & 174 & 43.2 \\
\hline Single & 208 & 51.6 \\
\hline Divorced & 9 & 2.2 \\
\hline Cohabitating & 12 & 3 \\
\hline \multicolumn{3}{|l|}{ Educational level } \\
\hline None & 4 & 1 \\
\hline Primary & 14 & 3.5 \\
\hline JHS & 101 & 25.1 \\
\hline SHS & 134 & 33.3 \\
\hline Tertiary & 150 & 37.2 \\
\hline \multicolumn{3}{|l|}{ Ethnic } \\
\hline Akan & 110 & 27.3 \\
\hline Ewe & 227 & 56.3 \\
\hline $\mathrm{Ga}$ & 39 & 9.7 \\
\hline Dagomba & 12 & 3 \\
\hline Other* & 15 & 3.7 \\
\hline \multicolumn{3}{|l|}{ Religion } \\
\hline Christianity & 345 & 85.6 \\
\hline Islam & 58 & 14.4 \\
\hline \multicolumn{3}{|l|}{ Area } \\
\hline Bla & 75 & 18.6 \\
\hline Kpeme & 70 & 17.4 \\
\hline Zongo & 57 & 14.1 \\
\hline Kpoeta & 60 & 14.9 \\
\hline Ahado & 50 & 12.4 \\
\hline Market & 91 & 22.6 \\
\hline \multicolumn{3}{|l|}{ Occupation } \\
\hline Artisan & 53 & 13.2 \\
\hline Civil/public servant & 54 & 13.4 \\
\hline Farming & 20 & 5 \\
\hline Professional & 51 & 12.7 \\
\hline Student & 105 & 26.1 \\
\hline Trading & 113 & 28 \\
\hline Unemployed & 7 & 1.7 \\
\hline \multicolumn{3}{|l|}{ Income } \\
\hline 200ghc and below & 159 & 39.5 \\
\hline 201 to $400 \mathrm{ghc}$ & 122 & 30.3 \\
\hline 401 to 600 & 57 & 14.1 \\
\hline 601 to 999 & 45 & 11.2 \\
\hline 1000 to 2000 & 20 & 5 \\
\hline
\end{tabular}

2.4. Data Collection. The study was based on a sample of 403 in the Hohoe township. A multistage sampling was used in selecting participants for the study. The first stage involved stratifying the Hohoe Municipality into various local 
divisions in terms of clans and randomly selecting those local areas to be included in the study (Bla, Kpeme, Zongo, Ahado, Kpoeta, and Market Area). In the second stage, a proportionate to population size was used to apportion the sample size to be drawn from each suburb. The third stage was selecting individuals to be included in the study. This study sought the help of three specially trained research assistants in the collection of data. A semistructured questionnaire was developed to conduct the face-to-face interviews. Most of the questions were drawn from the existing questionnaires. The rationale for the study was explained to participants, and those who voluntarily consented to participate were selected. Total anonymity and confidentiality of the respondents was assured; that is, no individual was identified with a particular instrument or information. The questionnaire was pretested, and all necessary corrections effected. The data solicited from the street food consumers were the types of street foods often purchased; the number of times individuals consumed street foods per week; the amount spent on street foods per week, and reasons for consuming street foods. Regarding the sociodemographic characteristics of the respondents, details relating to the gender, age, marital status, educational attainment, monthly income, occupation, and ethnicity were solicited.

2.5. Data Analysis. Data collected from the survey were entered in Excel sheets and later imported into STATA version 12 for analysis. Mean, median, mode, and standard deviation were reported for continuous variables and percentage for categorical variables. A $P$ value of $<0.05$ was considered significant in all the analyses. The characteristics of respondents explored in the analyses were gender, age, marital status, educational attainment, monthly income, occupation, and ethnicity. Chi-square tests were used to test for the association between demographics and reasons for street food consumption, demographics with concern towards safety of street food.

To determine the Dietary Diversity Score (DDS) of the respondents, a point was awarded to each food group consumed over the reference period, and a sum of all points was computed. A scale of thirteen food groups was used. Based on the food groups, dietary diversity terciles were established, namely, low dietary tercile ( $\leq 3$ food groups); medium diversity tercile (4 to 5 food groups); and high diversity tercile ( $\geq 6$ food groups). The respondent DDS was then assessed based on their position on the scale.

\section{Results}

3.1. Sociodemographic Characteristics. Table 1 shows the various demographic characteristics of the respondents for the study. Whilst majority of study participants were below the ages of 25 years, there were more males than females and was made up of predominantly the Ewe ethnic group followed by the Akans with a few other ethnic groups. Additionally, the majority of the respondents were traders, being followed by the student population with few artisans. The study revealed that more than half of the sample were never married whilst the rest were either married or divorced.

3.2. Types of Street Food Consumed. In Figure 1, results indicate that the top 5 foods mostly patronised by respondents are porridge foods, rice and stew, banku, waakye, and kenkey.

3.3. The Extent of Street Foods Consumption. Results from Table 2 indicate that respondents patronise street food at least once a week across all the food categories. It is important to note that porridge foods are consumed almost on a daily basis.

3.4. Individual Dietary Diversity Score. Out of the possible thirteen (13) food groups, the mean DDS was $7.60 \pm 2.24$, with scores ranging from 3-11 food groups. The DDS of most respondents was in the high tercile ( $\geq 6$ food groups) followed by the medium tercile ( 4 to 5 food groups). Only a few of the study participants were found to be in the lower tercile ( $\leq 3$ food groups). There was no significant association between demographic characteristics such as age, income, and level of education. However, the study found a relationship between dietary diversity and occupation, and this relationship is statistically significant.

3.5. Reasons for Patronising Street Foods. Results from Figure 2 indicate that convenience, inability to cook, and affordability were the main reasons why respondents patronise street foods. Additionally, accessibility and the readiness with which the food is available were also mentioned as playing an important role in the decision to purchase street food. The reasons for consuming street foods were also analysed based on the various demographic variables such as age, level of education, and gender, and the results are presented in Table 3. Further analysis indicates that gender, ethnicity, occupation, and income have no significant statistical relationship with the reasons why respondents prefer street food. On the other hand, the age of respondents correlated with the reason for choosing street food, and this is statistically significant. Convenience, inability to have enough time to prepare the meal, and affordability play a major role among the people younger ages. In addition, there is a relationship between the marital status and choice of street food which is also statistically confirmed by the present study. Single respondents found convenience and their inability to prepare meals at home to be the reason for their preference of street food over home meals.

A strong relationship was also observed between religion and street food preference which is significant statistically. It is important to note that there were more Christian respondents in the current study, and their reason for choosing street foods borders on convenience and the time to prepare home meals.

There was a significant statistical relationship between the study site and the reason for choosing street food from the current study. Another interesting finding from the 


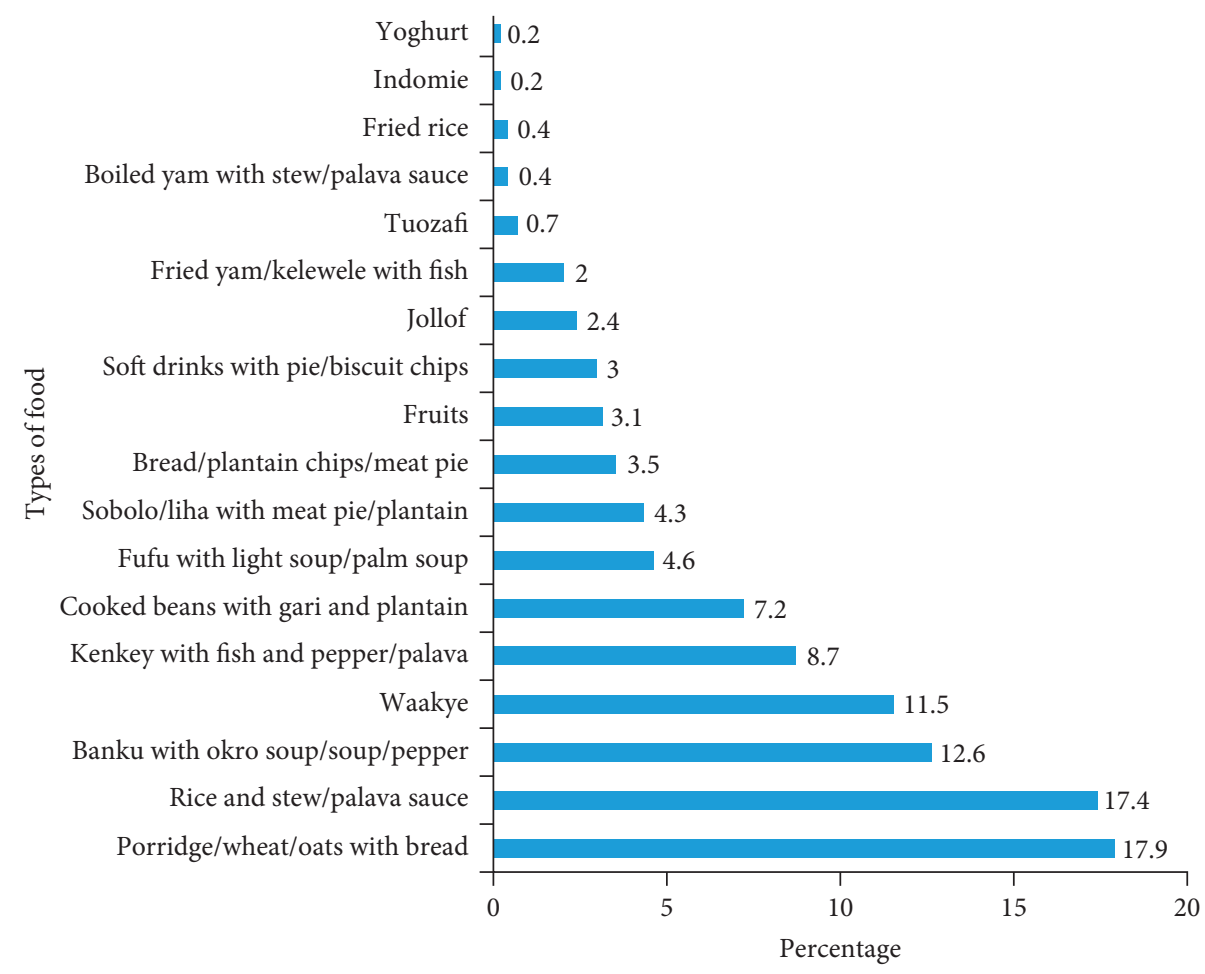

Figure 1: Types of street food consumed.

TABle 2: The extent of street foods consumption.

\begin{tabular}{|c|c|c|c|c|c|}
\hline Food type & Once a week & $2-4$ times & 5-6 times & Everyday & Total \\
\hline Rice with tomato stew or bean stew & $152(42.9)$ & $119(33.6)$ & $50(14.1)$ & $33(9.3)$ & $354(100)$ \\
\hline Banku/akple with tomato stew, okro stew, or pepper sauce & $117(34.6)$ & $133(39.4)$ & $42(12.4)$ & $46(13.6)$ & $338(100)$ \\
\hline Fufu or kokonte with light soup or palm fruit soup & $142(52.4)$ & $95(35.1)$ & $28(10.3)$ & $6(2.2)$ & $271(100)$ \\
\hline Ampesi with tomato stew or palava sauce & $99(54.7)$ & $55(30.4)$ & $22(12.2)$ & $5(2.8)$ & $181(100)$ \\
\hline Kenkey with fish and pepper sauce & $74(24.0)$ & $122(39.5)$ & $76(24.6)$ & $37(12.0)$ & $309(100)$ \\
\hline Koko (porridge) or tea with omelette and bread & $89(29.1)$ & $97(31.7)$ & $33(10.8)$ & $87(28.4)$ & $306(100)$ \\
\hline Waakye & $113(37.8)$ & $102(34.1)$ & $62(20.7)$ & $22(7.4)$ & $299(100)$ \\
\hline Cooked beans with gari and palm oil & $161(57.9)$ & $91(32.7)$ & $21(7.6)$ & $5(1.8)$ & $278(100)$ \\
\hline Fried yam/kelewele/plantain & $101(35.1)$ & $105(36.5)$ & $66(22.9)$ & $16(5.6)$ & $288(100)$ \\
\hline Fruits & $57(16.1)$ & $96(27.0)$ & $83(23.4)$ & $119(33.5)$ & $355(100)$ \\
\hline Soft drinks/cocoa drink/ice kenkey & $82(25.1)$ & $124(37.9)$ & $57(17.4)$ & $64(19.6)$ & $327(100)$ \\
\hline Tuozaafi & $40(42.1)$ & $22(23.2)$ & $5(5.3)$ & $28(29.5)$ & $95(100)$ \\
\hline
\end{tabular}

current study is the role of study site in determining the reason for choosing street food, thus, location. Whilst convenience plays an important role among residents of Zongo and Bla, residents in Kpeme opted for street food because of its accessibility. Additionally, inability to have enough time to cook was the reason the residents of Kpoeta would opt for street food.

Finally, a statistically significant relationship was observed between the level of education of the study participant and the reason for choosing street food. Accessibility, convenience, affordability, and inability to cook play an important role among respondents with an educational background above postbasic school.

3.6. Safety Concern towards Street Foods. From Table 3, there is a strong view among study participants on the safety of street food; however, there are no statistically significant differences in how respondents view the safety of street based on their age, gender, marital status, ethnicity, location, and income level. There is, however, a significant statistical relationship between the safety of street foods based on study participants' occupation and their level of education. Students were very much concerned about the safety with the least concerned raise by farmers. Additionally, respondents with postbasic education are much more concerned about the safety of street foods than those with a lower level of education, and this, according to the results presented in Table 3, is statistically significant.

\section{Discussion}

This study explored the nature and pattern of street food consumption among natives in the Hohoe township. The 




FIGURE 2: Reasons for consuming street foods.

TABLE 3: Relationship between various demographic variables and the dietary diversity score concern toward food safety, as well as reasons for consuming street foods.

\begin{tabular}{lll}
\hline $\begin{array}{l}\text { Dietary diversity score: mean }(\mathrm{SD})=7.60(2.24) \\
\text { Variable }\end{array}$ & Chi-squared & $P$ value \\
\hline Age & 14.8815 & 0.248 \\
Income & 12.4247 & 0.133 \\
Level of education & 15.0092 & 0.059 \\
Occupation & 25.5869 & 0.004 \\
\hline Concern toward food safety & & \\
Age & 12.0788 & 0.06 \\
Sex & 1.7579 & 0.185 \\
Marital status & 2.05 & 0.562 \\
Ethnicity & 6.6872 & 0.153 \\
Religion & 0.2651 & 0.607 \\
Area & 8.0017 & 0.156 \\
Occupation & 17.3094 & 0.008 \\
Income & 3.0818 & 0.544 \\
Educational level & 17.1731 & 0.002 \\
\hline Reasons for consuming street food & \\
Age & 54.4564 & 0.0001 \\
Sex & 4.7178 & 0.317 \\
Marital status & 34.1506 & 0.001 \\
Ethnicity & 30.8097 & 0.014 \\
Religion & 15.7689 & 0.003 \\
Area & 61.7288 & 0.0001 \\
Occupation & 34.5334 & 0.076 \\
Income & 24.6241 & 0.077 \\
Educational level & 46.4637 & 0.0001 \\
\hline
\end{tabular}

first objective was to determine the types of street food consumed by study participants. The top 5 food consumed as found by the study indicates that, in general, street food consumption follows a particular trend where most consumers heavily patronised carbohydrate foods. The great taste for carbohydrate staples may be associated with the culture of the people, the vegetation which provides an arable land for the production of carbohydrate rich foods, and cost implications. Traditionally, indigenes from the Volta Region are noted for eating Akple, food made from corn. As a result, the preference is likely to be placed for these groups of foods than any other foods, an indication of the dominant role the culture plays in the choice of food consumption, as well as the eating habit adopted by people. Additionally, cost is a variable that can influence choice of patronizing an item, and food is no exception. It could be that the cost involved in patronizing foods rich in carbohydrates is bearable; hence, people of all spheres of life can patronise irrespective of the socioeconomic status. Cost also has the potential of determining the quality and frequency at which specific food types can be bought. In essence, people opt to constant patronage of carbohydrates regardless of its health implications without adding protein and other minerals in the right proportion. This finding is very consistent with that of the previous studies [4, 7-10].

The current study also analyses the extent of street foods consumptions in the study area. The consumption of street food seemed to be a daily phenomenon. Plausible underlying cause for this huge patronage could come from the findings on the reason for patronising street food as found by the current study. Convenience, easy accessibility, and cost could play an important role in the extent to which street foods were consumed in the current study.

Additionally, the study also analysed the dietary diversity of foods consumed and found that there is diversity in the pattern of street food consumed among consumers despite the high preference for cereals. Food elements such as milk products rich in calcium and vitamins are patronised, but the frequency is rare. This could be the cost involved in buying such foods. Milk products, however, are good for teeth and bone formation as they are rich sources of calcium. This is the more reason why sensitization on dietary diversity is necessary to foster a good eating habit among consumers. They are important for bones and teeth, as well and aid the absorption of calcium, which is essential for the heart and colon. The association between occupation and dietary diversity could mean that students consumed a variety of foods as a result of their knowledge of the benefits of eating a variety of foods through education.

Another objective of the current study was to analyse the underlying factors that could influence the choice of street food. Aside cost, accessibility and availability were noted as factors triggering people to patronise street foods. Surprisingly, the inability to prepare food was also identified as a factor. As reported from the result, convenience is the major contributor to people patronizing street food, and this supports previous research [9-11]. Notably, street food vending has seen an appreciable expansion in Hohoe; hence, food vendors are nearly seen at every corner. In essence, there is competition in the food vending business forcing vendors to sell food at a more reduced price. Consequently, food as a commodity is inexpensive and people may not have to walk long distances before reaching the verge of a food vendor. The association between the marital status and choice of street food could mean that people who are single 
turn to consume street food more as some may perceive cooking as a waste of time. However, the trend may not be the same in married circumstances, a finding that is consistent with that of Hiamey et al. [3]. As tradition may have it, it is the sole responsibility of the woman to prepare meals for the family, and many societies in our part of the world frown on a married woman buying street foods on regular basis. In essence, the likelihood of a married man or woman going for street foods is only limited to some few instances. On the contrary, it seems easy for single men and women to resort to consumption of street foods.

Also, association with education revealed that the majority of tertiary students patronised street foods due to long hours spent on studies at the expense of food to eat. As revealed from this study, the majority of people in the study patronised street foods for its convenience which was consistent with earlier findings [9].

The study also indicates that the more educated people have better knowledge on food safety. In effect, such people are conscious of the cleanliness of the environment in which food is prepared and sold. The general view is that greater number of consumers had higher concerns towards food safety. The result is consistent with that of earlier studies where concerns about safety of street foods were highly raised [6-9].

\section{Conclusions}

The current study explored the nature and pattern of street consumption looking specifically at the types of street foods consumed, the extent of consumption, reasons behind patronizing street, and to understand consumers' concern and attitude towards the safety of the foods they consumed. Although there is no empirical evidence to show that street food consumption is on the rise, the current study has demonstrated that the preference for street food is very high. This is based on the premise that, on average, respondents were found to consume street foods six times a week. Looking at the higher consumption of street foods in the current study area, there is the need for public health officials to take a keen interest in the development. The greater link between street food vending and bacterial infections in Ghana and the low observance of personal hygiene by street food vendors suggests that there is a possibility of more and more people in the Hohoe Municipality being exposed to possible bacterial infection which can only be detected long after the person has left the vendor.

\section{Abbreviations}

BMI: Body Mass Index

DDS: Dietary Diversity Score

FAO: Food and Agriculture Organization.

\section{Data Availability}

The quantitative data used in the current study are available upon request from the corresponding author. E-mail: kananga@uhas.edu.gh.

\section{Ethical Approval}

Before commencement of data collection, the study was approved by the Ethical Review Committee (ERC) of the Ghana Health Service (GHS) (ID NO: GHS-ERC: 12710/16). Permission was also sought from the Hohoe Municipal Health Directorate concerning the study.

\section{Consent}

Written informed consent was obtained from all subjects. The objectives of the study and its procedures were also vividly explained to all participants. In addition, participants were made aware that their participation was entirely voluntary and that they had the right to refuse to participate or to withdraw from the study at any time and that all the information collected about them during the study will be treated confidentially.

\section{Conflicts of Interest}

The authors declare that they have no conflicts of interest.

\section{Authors' Contributions}

WEB and MKA contributed to the design of the study. WEB and EKN collected the data. MKA and EKN performed the analysis and interpretation of the research data. MKA and WEB drafted the first version of the manuscript. WEB, MKA, and EKN participated in the manuscript review. All authors read and approved the final manuscript.

\section{References}

[1] FAO, Food for the cities: Street foods, Food and Agriculture Organization, Rome, Italy, 2013, http://www.fao.org/fcit/ food-processing/street-foods/en/.

[2] G. F. Nicolò and M. Ag, Street Food Vending in West African Cities. Street Food: Culture, Economy, Health and Governance, Ag, p. 146, Routledge, Abingdon, UKRoutledge, 2014.

[3] S. E. Hiamey, F. E. Amuquandoh, and G. A. Boison, "Are we indeed what we eat? street food consumption in the market circle area of Takoradi," Nutrition and Health, vol. 22, no. 3-4, pp. 215-235, 2013.

[4] R. A. Tham, E. A.- Brempong, H. Vampere, E. A.- Gyan, and A. G. Akwasi, "Knowledge on food safety and food-handling practices of street food vendors in Ejisu-Juaben municipality of Ghana," Advances in Public Health, vol. 2020, pp. 1-7, 2020.

[5] I. Adam, S. E. Hiamey, and E. A. Afenyo, "Students' food safety concerns and choice of eating place in Ghana," Food Control, vol. 43, pp. 135-141, 2014.

[6] F. Bormann, O. Adzinyo, and L. Letsa, "Safety and hygiene status of street vended foods in Ho, Ghana," Journal of Hospitality Management and Tourism, vol. 7, no. 2, pp. 25-32, 2016.

[7] J. K. Hassan and L. W. T. Fweja, "Assessment of food safety knowledge and compliance to hygienic practices among street food vendors in zanzibar urban district," Current Journal of Applied Science and Technology, vol. 39, no. 7, pp. 59-72, 2020.

[8] N. P. Steyn, D. Labadarios, and J. H. Nel, "Factors which influence the consumption of street foods and fast foods in 
South Africa-a national survey," Nutrition Journal, vol. 10, no. 1, p. 104, 2011.

[9] V. Gupta, K. Khanna, and R. K. Gupta, "A study on the street food dimensions and its effects on consumer attitude and behavioural intentions," Tourism Review, vol. 73, no. 3, pp. 374-388, 2018.

[10] I. Monney et al., "Food hygiene and safety practices among street food vendors: an assessment of compliance, institutional and legislative framework in Ghana," Food and Public Health, vol. 4, no. 6, pp. 306-315, 2014.

[11] J. O. Mensah, R. Aidoo, and A. N. Teye, "Analysis of street food consumption across various income groups in the Kumasi Metropolis of Ghana," International Review of Management and Business Research, vol. 2, no. 4, p. 951, 2013. 